\title{
EFFECTIVENESS OF GABAPENTIN USAGE TOWARD REDUCING PAIN INTENSITY LEVEL AND QUALITY OF LIFE OF POST-STROKE NEUROPATHIC PATIENTS IN REGIONAL GENERAL HOSPITAL, WEST NUSA TENGGARA PROVINCE YEAR 2018
}

\author{
NURUL QIYAAM ${ }^{1 *}$, WIRAWAN ADIKUSUMA ${ }^{1}$, BAIQ LENY NOPITASARI ${ }^{1}$, TRI MURTI ANDAYANI ${ }^{2}$, AULIA AMINI ${ }^{3}$
}

${ }^{1}$ Department of Pharmacy, Faculty of Health Science, University of Muhammadiyah Mataram, Indonesia. ${ }^{2}$ Department of Pharmacy, Faculty of Pharmacy, University of Gadjah Mada, Yogyakarta, Indonesia. ${ }^{3}$ Department of Midwifery, Faculty of Health Science, University of Muhammadiyah Mataram, Indonesia. Email: nuqi.gra@gmail.com

Received: 08 January 2019, Revised and Accepted: 16 January 2019

\section{ABSTRACT}

Objective: Stroke is defined as a sudden loss of brain function due to blockade/rupture of the brain's blood vessels. Data collected by the Indonesian Stroke Foundation show that Indonesia ranks first in Asia as the country with the highest number of stroke sufferers. The purpose of this study was to determine the effectiveness of the use of gabapentin to reduce pain intensity and improve the quality of life of post-stroke neuropathic pain in NTB Province hospital patients.

Methods: This study was carried out in the period of June-July 2018. The population was all post-stroke neuropathic patients who received gabapentin therapy in regional general hospital, West Nusa Tenggara Province.

Results: The results of the study using questionnaire EQ-5D-3L after using gabapentin for 2 weeks. Patients experienced an improvement in the quality of life in each dimension items, namely the ability to walk/move from $6.7 \%$, no problem to $60 \%$, no self-care, $26.7 \%$ no problem to be $80 \%$ without problems, usual activities carried out from $13.3 \%$ had no problems to $46.7 \%$ had no problems, feeling of pain/discomfort from $60 \%$ having moderate problems to $60 \%$ had no problems, and anxiety/depression of $60 \%$ had no problem being $100 \%$ has no problem. While the measurement of the quality of life using the EQ-VAS questionnaire, there was a significant improvement in the quality of life between before and after using gabapentin at 32.66 .

Conclusion: The use of gabapentin has effectiveness on reduction of pain intensity and the quality of life of post-stroke neuropathic patients in regional general hospital, West Nusa Tenggara Province year 2018.

Keywords: Neuropathy, Post-stroke, Gabapentin, Pain intensity, Quality of life.

(C) 2019 The Authors. Published by Innovare Academic Sciences Pvt Ltd. This is an open access article under the CC BY license (http://creativecommons. org/licenses/by/4. 0/) DOI: http://dx.doi.org/10.22159/ajpcr.2019.v12i3.31035

\section{INTRODUCTION}

Stroke is defined as a sudden loss of brain function caused by the blockage or the rupture of blood vessels of the brain [1,2]. Pathological classification stroke is ischemic stroke and hemorrhagic stroke [3]. Based on the data from the American Heart Association, stroke is the world's second-leading cause of death in the age group of over 60 years and the fifth-leading cause of death in the age group of 15-59 years [4]. In the United States, it is recorded that almost every $45 \mathrm{~s}$ someone has a case of stroke, and every $4 \mathrm{~s}$ experienced a death due to stroke [5]. Medical treatment for post-stroke pain in Indonesia had already begun using tricyclic antidepressant groups such as amitriptyline and anticonvulsants groups such as gabapentin [6]. The response of patients using these two drugs is good but since 2013, both of them are no longer included in the list and price ceiling for the treatment of injury pain because of weak scientific evidence on the use of post-stroke pain so that the management of pain therapy post-stroke becomes less effective [7].

Several studies conducted a study comparing the therapeutic effects of gabapentin and amitriptyline in post-stroke with neuropathic pain. Both gabapentin and amitriptyline provided effective pain control in peripheral neuropathic pain. In addition, gabapentin was more effective, especially in paroxysmal shooting pain than other pain qualities [8]. The comparison between gabapentin and amitriptyline stated that there is no difference in the therapeutic effect of herniated nucleus pulposus [9]. This study aims to know the effectiveness of the usage of gabapentin to decrease pain intensity and improve the patients' quality of life with neuropathic post-stroke in Poly Neurosurgery of Regional General Hospital, NTB.

\section{METHODS}

This study uses quasi-experimental, before the patient is given informed consent to retrieve patient data prospectively using the Wong-Baker Faces Pain Rating Scale (WBFPRC) to measure the reduction in pain intensity [10], and a questionnaire Euroqol 5 Dimension (EQ-5D) is used to measure the quality of life [11], analysis of variance and $t$-test were performed to analyze the mean difference in visual analog scale (VAS) and EQ-5D scores between subgroups of patients [12] and assess the health condition of the patient, comprising from EQ-5D-3L to measure improve the patient's quality of life $[13,14]$. The research was conducted in Poly Neurosurgery of Regional General Hospital, NTB, in June-July 2018.

The samples in this study were all the stroke outpatients who undergo neuropathic pain in Provincial General Hospital, NTB, including inclusion and exclusion criteria. The effectiveness of therapy using Wong-Backer Faces Pain Rating Scale used to measure the reduction in pain intensity, EQ-5D-3L questionnaire, and EQ-VAS which is used to measure the patient's quality of life.

EQ-5D-3L questionnaire consists of five dimensions: Mobility, self-care, activities, pain/discomfort, and anxiety/depression and in every dimension have a level such as no problem, moderate problems, and extreme problems. Levels of perceived problems are marked with $(\sqrt{ })$ in each dimension and coded 1 in column 1 , column 2 is coded 2 , and 
column 3 coded 3. Description: Column 1 = No problem in mobility, self-care, activities, pain/discomfort, and anxiety/depression. Column 2 = Moderate problems in mobility, self-care, activities, pain/ discomfort, and anxiety/depression. Column $3=$ Extreme problems in mobility, self-care, activities, pain/discomfort, and anxiety/depression. EQ-VAS questionnaire (visual analog scale) is used to assess the health condition of the patient. A score of 100 is given for the best health conditions imaginable and a score of 0 for the worst health conditions that can be imagined. Questionnaires were given to patients before therapy and after 4 weeks of therapy.

\section{RESULTS}

In total, we recruited 15 study patients with post-stroke neuropathic. Demographic characteristics are summarized in Table 1. Patients age ranged from 20 to 83 years. Male accounted for 8 (53\%) and education level up to senior high school 12 (80\%).

Analysis of differences in pain intensity before and after gabapentin therapy to decrease pain intensity by the help of SPSS 16.0 for Windows, where the analysis uses paired sample $t$-test. Results of research conducted using the WBFPRC can be seen in Table 2 .

Quality of life can be seen from the questionnaire respondents EQ-5D-3L. Questionnaire EQ-5D-3L has five dimensions: Mobility, self-care, activities, pain/discomfort, and anxiety/depression and has three levels of problems faced by patients: No problems, moderate problems, and extreme problems. Results of research conducted using the EQ-5D-3L questionnaire can be seen in Table 3.

EQ-VAS questionnaire is used to assess the imaginable health condition. In this questionnaire, the best health condition imaginable is rated 100 and the worst health conditions are rated 0 . The results of the research conducted using the EQ-VAS questionnaire can be seen in Table 4 .

\section{DISCUSSION}

Based on Table 2, it showed a mean \pm standard deviation result for the before data which is $8.06 \pm 1.38$, after data $3.80 \pm 1.20$, and both the data have difference in results which is $4.26 \pm 0.18$ means that there is a decrease in pain as much as 4.26 in the treatment of gabapentin $2 \times 300$ medication for 2 weeks also strengthened by the results of a $\mathrm{p}<0.05$ so that there are significant differences in before and after treatment. This research may indicate that the use of gabapentin $300 \mathrm{mg} 2$ times daily for 2 weeks has effectiveness in reducing pain intensity, results from this study also strengthened with a previous study conducted where

Table 1: Baseline characteristics of participants $(n=15)$

\begin{tabular}{ll}
\hline Characteristics & $\mathbf{n}(\%)$ \\
\hline Gender & \\
$\quad$ Male & $8(53)$ \\
Female & $7(47)$ \\
Education level & \\
$\quad$ Up to senior high school & $12(80)$ \\
$\quad$ Undergraduate & $3(20)$ \\
Age (years) & \\
$\quad<60$ & $5(33)$ \\
$\geq 60$ & $10(67)$ \\
\hline
\end{tabular}

Table 2: Pain intensity difference before and after the use of gabapentin

\begin{tabular}{llll}
\hline Group & Mean \pm SD & $\boldsymbol{\Delta}$ & $\mathbf{p}$ \\
\hline Before & $8.06 \pm 1.38$ & $4.26 \pm 0.18$ & $0.029^{*}$ \\
After & $3.80 \pm 1.20$ & &
\end{tabular}

SD: Standard deviation. ${ }^{*} \mathrm{p}<0.05, \Delta$ : Increase adherence, $\mathrm{p}$ value of paired sample t-test, SD: Standard deviation gabapentin is effective in reducing the intensity of the neuropathic post-stroke pain [6].

This is consistent with the theory that gabapentin may take effect after 1-2 weeks of usage and help reduce pain when used for at least 2-3 months [6]. Gabapentin also has the effect of which can reduce pain in patients with painful diabetic neuropathy, it is supported by the previous studies that have been done using gabapentin to patients with painful diabetic neuropathy [15]. The previous studies conducted compared gabapentin with amitriptyline, where it was obtained that gabapentin amitriptyline is superior in terms of reducing pain [16].

Based on the results of the EQ-5D-3L questionnaire in Table 3 on the quality of life with five dimensions and three levels of problems that are checked by the patient showed patients with post-stroke neuropathic pain who used gabapentin experienced a perceived problem before using gabapentin, whether it be no problem, moderate problems, and extreme problems. The highest perceived problem is mobility which holds $73,3 \%$ from 11 of 15 total patients, three patients experience extreme problems, and one patient experiences no problem. Self-care is as much as $66.7 \%$ in experiencing moderate problems and no problem is experienced at a percentage of $26.7 \%$, and one patient experiences extreme problems. Patients also experienced problems in daily activities, $60 \%$ in moderate problems, $26.7 \%$ in extreme problems, and $13.3 \%$ in no problem. Pain/discomfort is experienced at a percentage of $60 \%$ in moderate problems and $40 \%$ in extreme problems. The least perceived problem is anxiety or depression where $40 \%$ of patients experience moderate problems and no problem is at $60 \%$. Even though the patient felt pain, most patients do not experience feelings of depression or anxiety with pain being felt.

After the usage of gabapentin for 2 weeks, the percentage of patients who experience pain/discomfort decreased from $60 \%$ in experiencing extreme problems to $40 \%$ in experiencing moderate problems. The percentage of mobility decreased from $73.3 \%$ to $40 \%$ in experiencing moderate problems and an increase in experiencing little to no problem from $6.7 \%$ to $60 \%$. Percentage of experiencing moderate problems in daily activities fell from $60 \%$ to $53.3 \%$. Self-care percentage of experiencing little to no problems increased from $66.7 \%$ to $80 \%$. This proves the effectiveness of gabapentin as a treatment of post-stroke neuropathic pain [17]

\section{CONCLUSION}

From the results of research conducted in NTB Regional General Hospital, it can be concluded that the measurement of pain intensity using the WBFPRC to measure the pain patients feel experienced a significant reduction in pain intensity between before and after the use of gabapentin as big as $4.26 \pm 0.18$. Measurement of quality of life using the EQ-5D-3L questionnaire to increase the quality of life in all its dimensions, namely mobility from $6.7 \%$ to $60 \%$ in experiencing no problem, self-care from $26.7 \%$ to $80 \%$ in experiencing no problem, daily activities from $13.3 \%$ to $46.7 \%$ in experiencing no problem, pain/discomfort from $60 \%$ of experiencing moderate problems to $60 \%$ of experiencing no problems, and anxiety/depression of $60 \%$ in experiencing no problem to $100 \%$ of experiencing no problem. Measurement of the quality of life using the EQ-VAS questionnaire to assess health conditions that can be imagined by the patient showed a significant increase in quality of life between before and after the usage of gabapentin in the amount of 32.66 .

\section{ACKNOWLEDGMENTS}

The authors thank the heads and staffs of the hospitals who assisted the researcher in conducting this research.

\section{AUTHOR'S CONTRIBUTIONS}

Nurul Q., Dr. Tri Murti A., Wirawan A., BQ Leni N., and Aulia A. contributed to the design of the case report and to the writing of the manuscript and have reviewed the article. 
Table 3: Patient response to every dimension of the EQ-5D-3L questionnaire

\begin{tabular}{|c|c|c|c|c|c|c|}
\hline \multirow[t]{2}{*}{ Dimension } & \multicolumn{3}{|c|}{ Before treatment } & \multicolumn{3}{|c|}{ After treatment } \\
\hline & NP, n (\%) & MP, n (\%) & EP, n (\%) & NP, n (\%) & MP, n (\%) & EP, n (\%) \\
\hline Mobility & $1(6.7)$ & $11(73.3)$ & $3(20)$ & $9(60)$ & $6(40)$ & $0(0)$ \\
\hline Daily activities & $2(13.3)$ & $9(60)$ & $4(26.7)$ & $7(46.7)$ & $8(53.3)$ & $0(0)$ \\
\hline Pain/discomfort & $0(0)$ & $9(60)$ & $6(40)$ & $9(60)$ & $6(40)$ & $0(0)$ \\
\hline Anxiety/depression & $9(60)$ & $6(40)$ & $0(0)$ & $15(100)$ & $0(0)$ & $0(0)$ \\
\hline
\end{tabular}

n: Number of patients, NB: No problem, MP: Moderate problems, EP: Extreme problems

Table 4: Euroqol-visual analog scale value before and after the use of gabapentin

\begin{tabular}{lll}
\hline Group & Mean \pm SD & p \\
\hline Before & $36.00 \pm 12.98$ & $0.028^{*}$ \\
After & $68.66 \pm 9.90$ & \\
\hline
\end{tabular}

${ }^{*} \mathrm{p}<0.05, \Delta$ : Increase adherence, the $\mathrm{p}$ value of a paired sample t-test,

SD: Standard deviation

\section{CONFLICTS OF INTEREST}

All authors have none to declare.

\section{REFERENCES}

1. Mason P. Medical Neurobiology. USA: Oxford University Press; 2011.

2. Chandrasekar K. Post-stroke psychiatric disorders: An overview on its screening and management. Asian J Pharm Clin Res. Available from: https://www.innovareacademics.in/journals/index.php/ajpcr/article/ view/26047. [Last accessed on 2019 Jan 08]

3. Heart Disease and Stroke Prevention Addressing the Nation's Leading Killers. Heart Dis; 2009.

4. Lackland DT, Roccella EJ, Deutsch AF, Fornage M, George MG, Howard G, et al. Factors influencing the decline in stroke mortality: A statement from the American Heart Association/American stroke association. Stroke 2014;45:315-53.

5. Available from: http://www.heart-disease-and-stroke-statistics-2018at-a-glance-ucm 498848.pdf.

6. Utami P, Ikawati Z, Setyaningsih S. Perbandingan efek terapi gabapentin dan amitriptilin pada pasien stroke dengan nyeri neuropati. Mutiara Med J Kedokt Dan Kesehatan 2016;13:89-97.

7. van Hecke O, Austin SK, Khan RA, Smith BH, Torrance N. Neuropathic pain in the general population: A systematic review of epidemiological studies. Pain 2014;155:654-62.

8. Keskinbora K, Pekel AF, Aydinli I. Periferik nöropatik ağrinin kontrolünde gabapentin ve amitriptilinin etkinliğinin karşilaştirilmasi. Agri 2006; 18:34-40.

9. Cahyaningsih I, Handayani R, Setyaningsih. The comparison of gabapentin and amitriptilin effectivity as pain therapy in herniated nucleus pulposus. Int J Public Health Sci 2015;4:225-31.

10. Home. Wong-Baker FACES Foundation. Available from: http://www. wongbakerfaces.org/. [Last accessed on 2018 Nov 27].

11. Balestroni G, Bertolotti G. EuroQol-5D (EQ-5D): An instrument for measuring quality of life. Monaldi Arch Chest Dis 2012;78:155-9.

12. Butt M, Ali AM, Bakry MM. Health-related quality of life in poorly controlled Type 2 diabetes patients-association of patients' characteristics with EQ-5D domains, mean eq-5d scores, and visaul analog scale score. Asian J Pharm Clin Res 2018;11:93-8.

13. Buchholz I, Janssen MF, Kohlmann T, Feng YS. A systematic review of studies comparing the measurement properties of the three-level and five-level versions of the EQ-5D. Pharmacoeconomics 2018;36:645-61.

14. Pattanaphesaj J, Thavorncharoensap M. Measurement properties of the EQ-5D-5L compared to EQ-5D-3L in the thai diabetes patients. Health Qual Life Outcomes 2015;13:14.

15. Gabapentin for Chronic Neuropathic Pain in Adults. Available from: http://www./CD007938/SYMPT_gabapentin-chronic-neuropathicpain-adults. [Last accessed on 2018 Nov 27].

16. Comparative Study of Safety and Efficacy of Gabapentin Versus Amitriptyline in Patients With Painful Diabetic Peripheral Neuropathy, A Randomized open Label Parallel Group Study. Biomedical and Pharmacology Journal. Available from: http://www. biomedpharmajournal.org/vol10no3/comparative-study-of-safety-andefficacy-of-gabapentin-versus-amitriptyline-in-patients-with-painfuldiabetic-peripheral-neuropathy-a-randomized-open-label-parallelgroup-study/. [Last accessed on 2018 Nov 27].

17. Hesami O, Gharagozli K, Beladimoghadam N, Assarzadegan F, Mansouri B, Sistanizad M, et al. The efficacy of gabapentin in patients with central post-stroke pain. Iran J Pharm Res 2015;14:95-101. 